\title{
Herança da Resistência aOS Herbicidas InIBIDORES da ALS em BıÓTIPOS DA PLANTA DANINHA Euphorbia heterophylla
}

\author{
Inheritance of ALS Inhibitor Resistance in Euphorbia heterophylla Weed Biotypes
}

VARGAS, L. ${ }^{2}$, BORÉM, A. ${ }^{3}$ e SILVA, A.A. ${ }^{3}$

\begin{abstract}
RESUMO - Os herbicidas inibidores da ALS são os principais produtos aplicados para o controle da planta daninha amendoim-bravo (Euphorbia herterophylla) em lavouras de soja; no entanto, já foram identificados biótipos desta planta daninha resistentes a estes herbicidas no Brasil. O objetivo desta pesquisa foi estudar a herança, o número de genes que conferem a resistência e o grau de resistência dos biótipos homozigotos e heterozigotos resistentes. Foram realizados cruzamentos recíprocos entre os genitores suscetiveis e resistentes para obtenção de sementes $\mathrm{F}_{1}$ e, posteriormente, realizaram-se os retrocruzamentos (RC) com os genitores resistente $(\mathrm{R})$ e suscetível (S). Plantas $\mathrm{F}_{1}$ foram autofecundadas artificialmente para obtenção da geração $\mathrm{F}_{2}$. As plantas $\mathrm{F}_{1}, \mathrm{~F}_{2}, \mathrm{RC}_{\mathrm{r}}$ e $\mathrm{RC}_{\mathrm{s}}$ e dos genitores foram tratadas com o herbicida imazethapyr ( $150 \mathrm{~g} \mathrm{ha}^{-1}$ ). Para avaliar o grau de resistência, plantas $\mathrm{F}_{1}$ e os genitores resistente e suscetivel foram tratados com as doses de imazethapyr de 0, 100, 200, 400,800 e $1.600 \mathrm{~g} \mathrm{ha}^{-1}$. As plantas $\mathrm{F}_{1}$ mostraram-se totalmente resistentes ao herbicida, demonstrando que a resistência é nuclear e dominante. As plantas $F_{2}$ apresentaram alta probabilidade para segregação 3:1, indicando que a resistência é codificada por um gene dominante. A aplicação de doses de imazethapyr sobre as plantas $\mathrm{F}_{1}$ demonstrou que os biótipos homozigotos resistentes e os heterozigotos apresentam o mesmo grau de resistência para doses de até $1.600 \mathrm{~g} \mathrm{ha}^{-1}$ deste herbicida. A resistência é codificada por um gene dominante nuclear com dominância completa.
\end{abstract}

Palavras-chave: resistência de plantas daninhas, hibridação, dominância, acetolactato sintase.

ABSTRACT - The ALS inhibitor herbicides are the main products applied to control Euphorbia heterophylla in the soybean crop; however, resistant biotypes to these herbicides have been identified in Brazil. This research aimed to study the inheritance, number of genes involved in the resistance and the degree of resistance of the homozygous and heterozygous resistant biotypes. Reciprocal crossings (RSs) were carried out between susceptible (S) and resistant (R) parents to obtain $F_{1}$ seeds. Individuals from $F_{1}, F_{2}, R C r$ and $R C s$ and parents were sprayed with imazethapyr $\left(150 \mathrm{~g} \mathrm{ha}^{-1}\right)$. To evaluate the resistance degree, $F_{1}$ plants and the resistant and susceptible parents were sprayed with imazethapyr $\left(0,100,200,400,800\right.$ and $\left.1,600 \mathrm{~g} \mathrm{ha}^{-1}\right) . \mathrm{F}_{1}$ plants were totally resistant to the herbicide, demonstrating that resistance is nuclear and dominant. $F_{2}$ presented high probability for 3:1 segregation, indicating that resistance is coded by a dominant gene. The experiment with $F_{1}$ plants sprayed with rates of imazethapyr, demonstrated that dominance is complete.

Key words: herbicide resistance, hybridization, dominance, inheritance, acetolatate synthase.

\section{INTRODUÇÃO}

O amendoim-bravo (Euphorbia heterophylla) é uma planta daninha herbácea, ereta, com 40-60 cm de altura, com ciclo de 2 a 3 meses e que se reproduz por sementes. É uma espécie com características variáveis - especialmente as folhas exibem grande variabilidade morfológica dentro de uma população - e nativa das regiões tropicais e subtropicais das américas.

1 Recebido para publicação em 24/7/2001 e na forma revisada em 17/12/2001.

2 Eng.-Agrônomo, D.S. Professor da Faculdade de Ciências e Tecnologia de Unaí, 38610-000 Unaí-MG. ${ }^{3}$ Eng.-Agrônomo, D.S. Professor da Universidade Federal de Viçosa-UFV, 36571-000 Viçosa-MG. 
É uma infestante com alta capacidade competitiva, com rápido crescimento e multiplicação (Kissmann \& Groth, 1992).

O uso repetido do mesmo herbicida ou de herbicidas com mesmo mecanismo de ação para controle de plantas daninhas tem exercido alta pressão de seleção, provocando mudanças na flora de algumas regiões. Em geral, espécies ou genótipos de uma espécie que melhor se adaptam a uma determinada prática são selecionados e multiplicam-se rapidamente (Holt \& Lebaron, 1990).

Os herbicidas pertencentes aos grupos químicos imidazolinonas e sulfoniluréias agem inibindo a enzima acetolactato sintase (ALS), também conhecida como acetoidroxiácido sintase (AHAS), que atua na rota de síntese dos aminoácidos valina, leucina e isoleucina (Hess, 1994). Esses herbicidas são largamente utilizados, devido à sua baixa toxicidade a animais, alta seletividade às culturas e alta eficiência mesmo em doses baixas. Aproximadamente cinco anos após o início do uso desses herbicidas surgiu o primeiro biótipo resistente (Powles \& Holtum, 1994). Evidências sugerem que o aparecimento de resistência a um herbicida em uma população de plantas se deve à seleção de um genótipo resistente preexistente, que, devido à pressão de seleção exercida por repetidas aplicações de um mesmo herbicida, encontra condições para multiplicação (Betts et al., 1992).

Existem diversos fatores relacionados à população de plantas que interagem e determinam a probabilidade e o tempo de evolução da resistência, dentre os quais se destacam: número de alelos envolvidos na expressão da resistência; freqüência do(s) alelo(s) da resistência na população inicialmente suscetível; modo de herança do(s) alelo(s) da resistência (materna ou paterna); características reprodutivas da espécie; pressão de seleção; e taxa de cruzamentos entre biótipos resistentes e suscetíveis (Mortimer, 1998).

Quanto maior o número de genes envolvidos na resistência, menor será a probabilidade de surgir biótipos resistentes em uma população. A freqüência de alelo de resistência nas populações nativas geralmente está entre $10^{-16}$ e $10^{-6}$ (Mortimer, 1998), e, quanto maior for a freqüência do alelo, maior será a probabilidade de seleção de um biótipo resistente.
O tipo de herança é um aspecto importante no estabelecimento da resistência em uma população de plantas. Existem dois tipos de herança: a citoplasmática (materna) e a nuclear. Herança citoplasmática é aquela em que os caracteres hereditários são transmitidos via citoplasma; assim, somente a planta-mãe transmitirá a resistência para os descendentes. Um exemplo são as plantas resistentes às triazinas. Por outro lado, se a herança for nuclear, tanto o pai quanto a mãe podem transmiti-la.

O processo da evolução da resistência a herbicidas, resumidamente, passa por quatro estádios: eliminação dos biótipos altamente suscetiveis, restando apenas os mais tolerantes e resistentes; eliminação de todos os biótipos, exceto os resistentes, e seleção destes dentro de uma população com alta tolerância; intercruzamento entre os biótipos sobreviventes, gerando novos indivíduos com maior grau de resistência, que serão selecionados futuramente; e segregação e recombinação de genes (Mortimer, 1998).

Biótipos resistentes podem ocorrer em uma população de plantas daninhas como resultado de mutações que provocam alterações no local de ação do herbicida. Uma pequena alteração no polipeptídio pode resultar em grande efeito sobre a afinidade com a molécula herbicida (Betts et al., 1992). A resistência de Arabidopsis thaliana às imidazolinonas se deve à alteração de um aminoácido da ALS (Sathasivan et al., 1991). A resistência a imidazolinonas e sulfoniluréias é conferida por um gene dominante nuclear (Mazur \& Falco, 1989; Powles \& Holtum, 1994).

O uso repetido de herbicidas inibidores da ALS, em lavouras de soja nos Estados do Rio Grande do Sul e Mato Grosso do Sul, levou à seleção de biótipos de Bidens pilosa resistentes a esses herbicidas (Ponchio, 1997). Biótipos de E. heterophylla resistentes a imidazolinonas vêm sendo observados em lavouras de soja no Estado do Rio Grande do Sul e acredita-se que o uso repetido de herbicidas desse grupo seja a causa desse fenômeno.

O conhecimento dos mecanismos e fatores que favorecem o aparecimento de biótipos de plantas daninhas resistentes é fundamental para que técnicas de manejo sejam utilizadas no sentido de evitar ou retardar o seu aparecimento (Christoffoleti et al., 1994). O 
objetivo deste trabalho foi estudar o tipo de herança, o número de genes que conferem a resistência e o grau de resistência dos biótipos de $E$. heterophylla homozigotos e heterozigotos resistentes aos inibidores da ALS.

\section{MATERIAL E MÉTODOS}

Os experimentos foram conduzidos em casa de vegetação na Universidade Federal de Viçosa, em 1999.

Para obtenção dos genitores homozigotos resistentes e homozigotos suscetiveis, foram realizadas autopolinizações em 72 plantas de amendoim-bravo resistentes e em seis suscetíveis. As sementes produzidas em cada planta autopolinizada foram colhidas e armazenadas separadamente e mantidas em geladeira a $4-5^{\circ} \mathrm{C}$ durante cinco dias, para quebra da dormência. Para testar a homozigose, foram semeadas, de cada planta autopolinizada, 20 sementes em uma bandeja contendo $10 \mathrm{~kg}$ de solo. Quando as progênies atingiram estádio de 3-4 folhas, aplicou-se o herbicida imazethapyr, na dose de $200 \mathrm{~g} \mathrm{ha}^{-1}$. Todos os genitores onde ocorreu morte de pelo menos uma planta, entre as 20 testadas, foram descartados, e os demais foram considerados homozigotos resistentes ao herbicida. Por outro lado, foram considerados homozigotos suscetiveis aqueles genitores em que todas as 20 plantas testadas mostraram-se suscetíveis ao tratamento herbicida. Foram selecionados 69 genitores homozigotos resistentes e seis homozigotos suscetíveis ao imazethapyr.

Para realizar os cruzamentos, selecionouse um genitor homozigoto resistente e um homozigoto suscetivel. Sementes de cada genitor foram semeadas em vasos contendo $3 \mathrm{~kg}$ de solo. Após a emergência das plantas procedeuse ao desbaste, deixando uma planta por vaso. A adubação química (250 kg ha-1 de 5-20-20) foi realizada na instalação do experimento, obedecendo à análise química do solo.

Foram feitos cruzamentos recíprocos entre os genitores suscetíveis e resistentes para obtenção de sementes $\mathrm{F}_{1}$. Posteriormente, foram realizados retrocruzamentos entre plantas $\mathrm{F}_{1}$ e os respectivos genitores masculinos e femininos resistentes $\left(R_{r}\right)$ e suscetíveis $\left(R_{s}\right)$. Sementes $F_{1}$ foram semeadas em vasos, e as plantas originadas destas sementes foram autofecundadas para obtenção da $\mathrm{F}_{2}$. As sementes $\mathrm{F}_{1}, \mathrm{~F}_{2}, \mathrm{RC}_{\mathrm{r}}$ e $\mathrm{RC}_{\mathrm{s}}$ e dos genitores foram semeadas em bandejas com capacidade para $10 \mathrm{~kg}$ de solo; após a aplicação do herbicida imazethapyr ( $150 \mathrm{~g} \mathrm{ha}^{-1}$ ), avaliou-se a sua reação ao herbicida. As freqüências das classes obtidas foram testadas pelo teste qui-quadrado.

Foram semeadas, em bandejas contendo $10 \mathrm{~kg}$ de solo, as sementes $\mathrm{F}_{1}$ e dos genitores resistente e suscetivel. As plantas originadas destas sementes foram tratadas com doses crescentes de imazethapyr $(0,100,200,400$, 800 e $1.600 \mathrm{~g} \mathrm{ha}^{-1}$ ).

\section{RESULTADOS E DISCUSSÃO}

O número total de plantas, o número de plantas resistentes e suscetíveis, as relações observadas e esperadas, bem como os valores do teste $\chi^{2}$ e as respectivas probabilidades, estão contidos na Tabela 1 . A Figura 1 representa um retrocruzamento suscetivel (RCs) com segregação resistente suscetivel 1:1.

Os genitores resistente (R) e suscetivel (S) confirmaram, respectivamente, sua resistência e suscetibilidade ao herbicida.

No primeiro cruzamento suscetivel x resistente ( $\mathrm{S} \times \mathrm{R})$, a $\mathrm{F}_{1}$ apresentou-se totalmente resistente, demonstrando que a resistência é transmitida hereditariamente e é dominante. A população $\mathrm{F}_{2}$ apresentou segregação resistente/suscetivel 3,1:1, com teste qui-quadrado fornecendo probabilidade de $82 \%$ de esta ser 3:1. O retrocruzamento suscetivel (RCs) apresentou segregação resistente/suscetível 0,9:1, com probabilidade de 90\% de ser 1:1 (Figura 1). Já o retrocruzamento resistente (RCr) apresentou plantas totalmente resistentes, evidenciando, também, o caráter dominante da resistência. Todos esses resultados são concordantes entre si.

No cruzamento recíproco, resistente $\mathrm{x}$ suscetível ( $\mathrm{R} \times \mathrm{S})$, a geração $\mathrm{F}_{1}$, como no primeiro cruzamento, mostrou-se totalmente resistente, indicando que a resistência também é transmitida hereditariamente pela planta-mãe e, novamente, que a resistência é uma característica dominante. A população $\mathrm{F}_{2}$ apresentou segregação resistente/suscetivel $3,1: 1$, com probabilidade de $79 \%$ de ser 3:1. O RCs apresentou segregação 1,1:1, com probabilidade de $70 \%$ de ser $1: 1$. O RCr apresentou-se, novamente, totalmente resistente. 
Tabela 1 - Avaliação da segregação de cruzamentos, retrocruzamentos e cruzamentos recíprocos entre genótipos de Euphorbia heterophylla suscetíveis (S) e resistentes (R) aos herbicidas inibidores da ALS. Viçosa-MG,1999

\begin{tabular}{|c|c|c|c|c|c|c|c|}
\hline \multirow{2}{*}{ Cruzamentos } & \multirow{2}{*}{$\begin{array}{l}\text { Número de } \\
\text { Plantas }\end{array}$} & \multirow{2}{*}{ Resistentes } & \multirow{2}{*}{ Suscetíveis } & \multicolumn{2}{|c|}{ Relação } & \multirow{2}{*}{$\chi^{2}$} & \multirow{2}{*}{ Probabilidade } \\
\hline & & & & Esperada & Observada & & \\
\hline Suscetíveis (S) & 150 & 0 & 150 & - & - & - & - \\
\hline Resistentes (R) & 137 & 137 & 0 & - & - & - & - \\
\hline \multicolumn{8}{|l|}{ S x R: } \\
\hline $\mathrm{F}_{1}$ & 73 & 73 & 0 & $1: 0$ & $1: 0$ & 0,000 & 1,00 \\
\hline $\mathrm{F}_{2}$ & 170 & 129 & 41 & $3: 1$ & $3,1: 1$ & 0,070 & 0,82 \\
\hline $\mathrm{RCs}$ & 61 & 30 & 31 & $1: 1$ & $0,9: 1$ & 0,016 & 0,90 \\
\hline $\mathrm{RCr}$ & 61 & 61 & 0 & $1: 0$ & $1: 0$ & 0,000 & 1,00 \\
\hline \multicolumn{8}{|l|}{ R x S: } \\
\hline $\mathrm{F}_{1}$ & 64 & 64 & 0 & $1: 0$ & $1: 0$ & 0,000 & 1,00 \\
\hline $\mathrm{F}_{2}$ & 203 & 154 & 49 & $3: 1$ & $3,1: 1$ & 0,080 & 0,79 \\
\hline $\mathrm{RCs}$ & 82 & 43 & 39 & $1: 1$ & $1,1: 1$ & 0,190 & 0,70 \\
\hline $\mathrm{RCr}$ & 66 & 66 & 0 & $1: 0$ & $1: 0$ & 0,000 & 1,00 \\
\hline
\end{tabular}

$\mathrm{O}$ valor de $\chi^{2}$ fornece a probabilidade de as diferenças entre as relações esperada e observada serem devidas ao acaso. Graus de liberdade $=1$

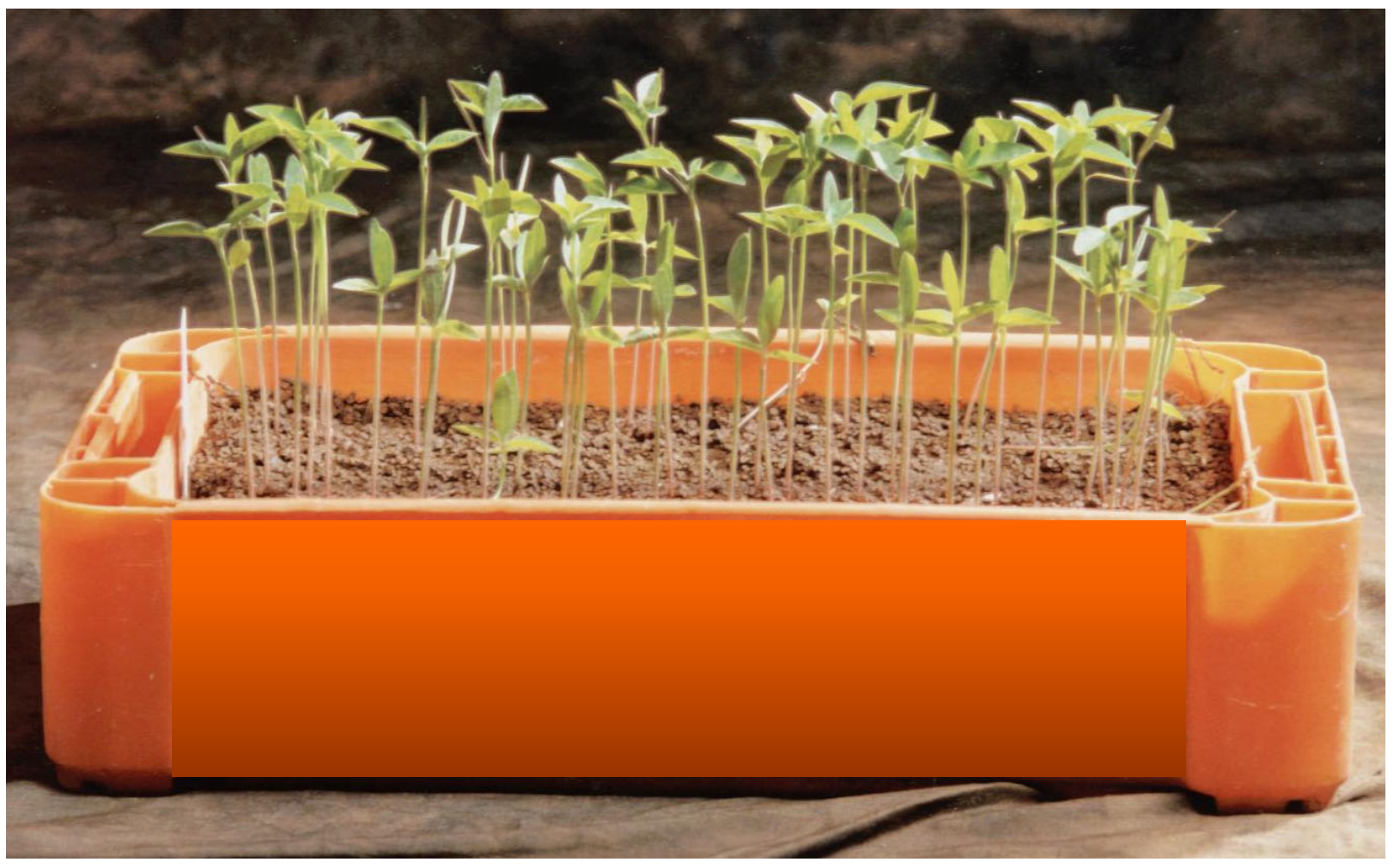

Figura 1 - Retrocruzamento suscetível (RCs) após tratamento com o herbicida imazethapyr (150 g ha $\left.{ }^{-1}\right)$, com segregação resistente/ suscetível 1:1. Plantas resistentes apresentam maior altura, e as suscetíveis, menor. Viçosa, MG,1999. 
A população $\mathrm{F}_{1}$, em ambos os cruzamentos, mostrou-se totalmente resistente ao herbicida, demonstrando que a resistência é dominante e nuclear. Esses resultados são confirmados pelos retrocruzamentos analisados. As populações $\mathrm{F}_{2}$ apresentaram alta probabilidade para o padrão de segregação 3:1, indicando que a resistência é codificada por um gene dominante. Esses resultados estão de acordo com Mazur \& Falco (1989), Mallory-Smith et al. (1990) e Powles \& Holtum (1994).

Esses resultados sugerem que a resistência apresentada pelos biótipos de amendoim-bravo é codificada por um gene dominante nuclear. As características com herança do tipo nuclear têm disseminação rápida na população, via pólen, em espécies de fecundação cruzada. Contudo, a taxa de alogamia em amendoimbravo não é conhecida; portanto, não é possível fazer previsões da disseminação deste gene em uma área.

A avaliação das plantas $F_{1}$ com doses crescentes de imazethapyr demonstrou que as plantas homozigotas resistentes e as heterozigotas apresentam o mesmo grau de resistência para doses de até $1.600 \mathrm{~g} \mathrm{ha}^{-1}$ do herbicida e que as plantas suscetiveis morrem com a dose de $100 \mathrm{~g} \mathrm{ha}^{-1}$. O trabalho realizado por Seefeldt et al. (1998) demonstra que biótipos heterozigotos de Avena fatua, resistentes ao diclofop, apresentam grau intermediário de resistência ao herbicida. No trabalho destes autores, os biótipos homozigotos suscetiveis e os heterozigotos foram controlados com as doses de 0,55 e 1,1 kg ha-1 de diclofop, respectivamente. Já o biótipo homozigoto resistente não foi controlado com a dose de $5,5 \mathrm{~kg} \mathrm{ha}^{-1}$ do mesmo herbicida.

Assim, apesar de as plantas heterozigotas de amendoim-bravo apresentarem o alelo recessivo (suscetivel), elas são igualmente resistentes àquelas homozigotas resistentes, que apresentam os dois alelos dominantes (resistentes), sugerindo ação gênica com dominância completa. Esse fato tem implicações práticas importantes, já que, em lavouras infestadas com estas plantas de amendoim-bravo resistentes, o aumento da dose deste herbicida não proporcionará aumento no controle. Assim, a recomendação de aumento da dose do herbicida não é tecnicamente justificável.

\section{CONCLUSÕES}

Com base no que foi exposto, conclui-se:

- A resistência aos herbicidas inibidores de ALS em Euphorbia heterophylla é controlada por um alelo nuclear dominante.

- Não há diferenças no grau de resistência entre os biótipos homozigotos resistentes e heterozigotos quando submetidos a aplicações de até $1.600 \mathrm{~g} \mathrm{ha}^{-1}$ de imazethapyr, sugerindo se tratar de um caso de dominância completa para este gene.

\section{LITERATURA CITADA}

BETTS, K.J.; EHLKE, N.J.; WYSE, D.L.; GRONWALD, J.W.; SOMERS, D.A. Mechanism of inheritance of diclofop resistance in Italian ryegrass (Lolium multiflorum). Weed Sci., v.40, n.2, p.184-189, 1992.

CHRISTOFFOLETI, P.J.; VICTÓRIA FILHO, R.; SILVA, C.B. Resistência de plantas daninhas aos herbicidas. Planta Daninha, v.12, n.1, p.13-20, 1994.

HESS, F.D. Mechanism of action of inhibitors of amino acid biosynthesis. In: HERBICIDE ACTION COURSE, 1994. Summary of lectures, West Lafayette, Purdue University, 1994.p.1023.

HOLT, J.S.; LeBARON, H.M. Significance and distribution of herbicide resistance. Weed Technol., v.4, n.1, p.141-149, 1990.

KISSMANN, K.G.; GROTH, D. Plantas infestantes e nocivas. São Paulo: Basf Brasileira, 1992. 798p. T II.

MALLORY-SMITH, C.A.; THILL, D.C.; DIAL, M.J.; ZEMETRA, R.S. Inheritance of sulfonylurea herbicide resistance in Lactuca spp. Weed Technol., v.4, n.4, p.787-790, 1990.

MAZUR, B.J.; FALCO, S.C. The development of herbicide resistant crops. Ann. Rev. Plant Physiol. Plant Molec. Biol., v.40, p.441$470,1989$.

MORTIMER, A.M. Review of graminicide resistance. 1998. Web: Http://ipmwww.ncsu.edu/orgs / hrac/monograph1.htm, 32p.

Planta Daninha, Viçosa-MG, v.19, n.3, p.331-336, 2001 
PONCHIO, J.A.R. Resistência de biótipos de Bidens pilosa L. a herbicidas inibidores da enzima ALS/ AHAS. Piracicaba: ESALQ, 1997. 143p. Tese (Doutorado em Fitotecnia) - Escola Superior de Agricultura "Luiz de Queiroz”, 1997.

POWLES, S.B.; HOLTUM, J.A.M. Herbicide resistance in plants: biology and biochemistry. Boca Raton, CRC Press, 1994. 353p.
SATHASIVAN, K.; HAUGHN, G.W.; MURAI, N Molecular basis of imidazolinone herbicide resistance in Arabidopsis thaliana var columbia. Plant Physiol., v.97, p.1044-1050, 1991.

SEEFELDT, S.S.; HOFFMAN, D.L.; GEALY, D.R.; FUERST, E.P. Inheritance of diclofop resistance in wild oat (Avena fatua L.) biotypes from the Willamette Valley of Oregon. Weed Sci., v.46, n.2, p.170-175, 1998. 